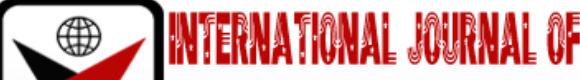

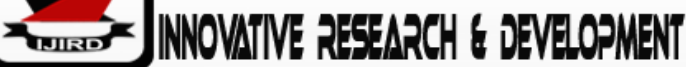

ISSN 2278-0211 (Online)

\section{Guidelines for Choosing a Good Research Topic in Education}

\author{
Dr. Chikwe, Christian K. \\ Associate Professor, Department of Educational Psychology, Guidance and Counseling, \\ Ignatius Ajuru University of Education, Rivers State, Nigeria
}

\begin{abstract}
:
Research plays prominent roles in the lives of individuals, organizations, or society in general. Every now and then, research breaks new grounds which help to bring about development and progress in every field of human endeavor. Effective research activities and efforts begin with choosing good research topics. This paper addresses the guidelines that will make for choosing good topics in education. The meaning, characteristic, types of research, the research process and ethical issues in research were also considered. The paper posited that identifying a problem, understanding the magnitude and dimension of the problem, feasibility, acceptability, etc. should be considered in choosing research topics.
\end{abstract}

Keywords: Research, education, research topic

\section{Introduction}

Man is always faced with a lot of problems and challenges. In order to find solution to these problems, man asks series of questions. The process of seeking for answers and arriving at dependable solutions to the problems is what research is all about. The problems could be in the field of education, science and technology, social science, arts, environmental health, etc.

The word research consists of two parts, 're' and 'search'. 'Re' is a prefix that means over again or repeat, while 'search' is a verb that means look at closely or examine closely and carefully. Research therefore, means a repeated and close examination to arrive at a solution.

The term or concept research has been defined by various authorities, experts in almost all fields of human endeavour. Ajoku (2006) defined research as the search for knowledge, truth, similarities and relationships; and the process of finding solutions to problems through systematic collection, analysis and interpretation of data. Maduabum (2007) explained that research is a means by which man seeks to discover truth; and defined research as a systematic application of the scientific method to the study of a problem. Also, Dike as cited in Adiele (2016:2) defined research as 'that branch of study concerned with the extension of the frontiers of knowledge in a field through the application of formal inquiry techniques or through the application of systemic procedures for data collection, analysis and reporting'. Adiele (2016) explained that in a generic sense, research is the application of scientific method in carrying out an investigation into the problems of man and presenting the result in a logical and sequential manner. Kpolovie (2010:3) defined research as

'the logical, systematic and objective collection, analysis, evaluation and recording of accurate and controlled observations for the development of generalizations, principles, or theories that are ultimately aimed at description, explanation, prediction and control of natural phenomena to meet specific needs of man'.

Educational research is a branch of research, concerned with the application of research to the solution of educational problems. Ukwuije (2007) defined educational research as 'the systematic approach employed by researchers; students in education to identify problems, investigate the problems and based on the findings offer suggestion as how to solve the problems'. Travers in Ajoku (2006) defined educational research as an activity directed toward the development of an organized body of scientific knowledge about the events with which educators are concerned. Also, Ary, Jacobs, Razavieh in Ajoku (2002) defined educational research as the way in which one acquires dependable and useful information about the educative process. In the same vein, Ahiakwo (2003) explained educational research as a diligent and systematic attempt to provide plausible answers to educational problems by the process of logically designed operations or steps. Anusiem (1992) sees educational research as an organized and systematic activity towards identification and solution of education problems aimed at extending the frontiers of knowledge. Ndagi in Ausiem (1992:16) defined educational research as 'a scientific method of controlled enquiry involving a systematic and intensive process of verifying knowledge that will help educationalists achieve their goals'. Such goals according to Traverse in Ausiem (1992), are discovery of laws or generalizations about behaviour which can be used to make predictions and control events within the educational situations. Educational research provides the framework within which the process and the product of our educational system could be brought under critical questioning and critical justification. The American Educational Research Association (2017) defined education (educational) research 'as the scientific field of study that examines education and 
learning processes and the human attributes, interactions, organizations, and institutions that shape educational outcomes. Educational research seeks to describes, understand and explain how learning takes place throughout a person's life and how formal and informal contexts of education affect all forms of learning. Educational research embraces the full spectrum of rigorous methods appropriate to the questions being asked and also drives the development of new tools and methods'(Retrieved from www.aera.net/About-AERA/What is Education Research on 20/5/2017.

Research therefore, is the systematic process of collecting, analyzing and interpreting data objectively with the purpose of improving knowledge and development of new phenomena for the benefit of man and society.

The importance of research to man and society cannot be overemphasized. Through research activities, new subject areas have emerged, the world is now a global village, there are breakthroughs in science and technology, improvement in health, health education, business, politics and economics are being recorded.

Research is different from other sources of knowledge or means by which man tries to find solutions to problems. The difference lies in the fact that research is based on scientific method which adopts clearly identifiable procedure. Other sources of knowledge are intuition, authority, reasoning or rationalization, experience or empiricism and common sense. Intuition is the process of solving problems or acquiring knowledge through interaction with divine source such as dreams, prophecy, premonition, gods or the supreme God. Authority is a method that relies on the opinions of highly respected people, scholars or authority in solving a problem. Reasoning is the process of arriving at solutions through rational thinking. Reasoning could be deductive (one proceeds from general to specific statement through prescribed rules or logic) or inductive (one proceeds from specific to the general). Experience is the use of accumulated knowledge or skills acquired from encounters in the environment to solve problems, common sense which uses common sense to arrive at solutions.

Ugodulunwa (2016) identified some characteristics of research as follows:

- Research is systematic: It consists of sequential steps that lead to solution of problems under study.

- Research is objective: The researcher's personal opinions, biases and prejudices do not influence the result of the investigation. There is objectivity in the observation, collection of data, reporting of results and drawing of conclusions and inferences.

- $\quad$ Research is empirical: It involves careful data collection for analysis using different methods and techniques such as interview, questionnaire, tests, observation, etc.

- Research is replicable: Other researchers can repeat earlier studies in order to verify their veracity and correctness.

- $\quad$ Research has a clear goal: The ultimate goal of a research are clearly and precisely stated.

- Research is cyclical in nature: Research starts with a problem and ends with conclusions which may sometimes initiate further problems for investigation.

- Research is non-ethical: It does not consider ethical issues that demand right or wrong, rather it tries to provide explanation for any actions.

- Research is a painstaking and expensive activity: It is painstaking because it demands a lot of courage and perseverance from the researcher. Research is expensive because it demands a lot of time, effort and resources in its execution.

\section{Classifications/Types of Research}

Research is classified in different ways. The classification leads to types of research. Therefore research is classified based on purpose, method, whether experimental or non-experimental and whether it is quantitative, qualitative or mixed methods.

Classification based on purpose: When classification is based on purpose, we have the following types of research:

- Basic or fundamental or pure research: Basic research is carried out for advancement of knowledge and development of new theories in a specific field. In psychology, the B.F Skinner's operant conditioning experiment is an example of basic research.

- Applied research: This is concerned with testing the applicability of theories in real life situations. Applied research tests the practicability of theories produced by basic research. Hence basic and applied research complements each other.

- Action research: This is conducted for solving immediate and pressing practical problems in different fields. The findings of this kind of research, is not generalized beyond the scope of the study. For example a department may decide to investigate into causes of poor quality of students' research projects in education.

- $\quad$ Research and development (R\&D): R\&D is concerned with developing new products and technologies such as textbooks, assessment instruments, curricula and instructional materials.

- Evaluation Research: This is concerned with making decisions about the effectiveness or desirability of programmes, methods and materials based on available data. It is a concerned with making decisions relating to value or worth of programmes based on empirical data. Example of evaluation research include: (i) evaluation of availability and utilization of instructional materials. It may be evaluation of input, process or outcomes of development project, intervention or curriculum.

Classification Based on Method: This is the classification of research according to the method adopted in the conduct of any research activity. Under this classification we have the following types of research:

- Historical research: This involves studying events that happened in the past with a view to improving on observed lapses in order to avoid future occurrences. Some aspects of the past are studied either through document 
analysis or by interviewing individuals who lived during the period. In historical research there are two sources of data - primary and secondary data. Primary sources are data provided by witnesses to the event in question. They are data original to the problem under study. Examples include relics, documents such as manuscripts, constitution, deeds, official minutes, biography, photographs, research reports, etc. Secondary sources are data that are not original. They are second hand information. They are stories narrated by informants, encyclopedias, quoted materials, etc. Example: (i) emerging trends in programme evaluation from 2000 to 2015.

- Survey research: This is the type of research whereby data is collected on a large representative sample of a given population. The representative sample is studied for the purpose of generalizing the findings to the population from where the sample is drawn. In survey research, the appropriate sampling (random, stratified random, systematic, cluster, quota, incidental, multi-stage, etc) and data collection techniques (questionnaires, interview, observation, test, etc) are used.

- Case study: This is an in-depth study of an individual, a group, an institution or a community geared towards thorough understanding of the social unit under investigation.

- Correlational research: This is the type of research that seeks relationship among variables. It is also used for making predictions.

- Causal comparative or ex-post facto research: This is the type of research where the researcher has no control over variables and cannot manipulate them. The effect of independent variable on the dependent variable is studied in retrospect or after they have had their effects. Examples include influence of gender on managerial skills on of environmental health officers; and effects of school environment on students' academic achievement.

- Experimental research: This type of research directly tests cause-and-effect relationships. In this type of research, the independent variable is manipulated to observe its effect on the dependent variable.

Classification according to whether research is quantitative or qualitative.

- Quantitative research: This type of research emphasizes numbers, measurement, deductive reasoning, control and experiments. Quantitative research has clearly stated questions and hypotheses. It also has well developed research procedures, controls extraneous variables, deals with large samples and involves statistical analysis of data. Quantitative research can be classified as experimental and non-experimental.

- Qualitative research: This type of research emphasizes understanding, meaning, verbal narratives and observations. Qualitative research deals with non-numerical or categorical data and it is typically used in anthropological and sociological research. Qualitative research involves observations of natural setting and indepth descriptions of situations. Qualitative research can be in the form of case studies, ethnographic research or content analysis of documents.

Research is a scientific method that follows a number of sequential steps. The steps are:

- Problem identification and definition (topic)

- Review of relevant literature

- Formulation of research questions and hypotheses

- Design of the study

- Data collection

- Analysis of data

- Drawing of inferences/conclusions

- Writing the report

\subsection{Ethical Issues in Research}

Ethics are moral principles that control individual's behaviour. They are norms for conduct that distinguish acceptable and non-acceptable behaviour (Resink cited in Ugodulunwa, 2016). These ethical issues identified by Resink include:

- Honesty - in reporting data, results, methods, procedures and publications.

- Objectivity - by avoiding bias in experimental design, data analysis, data interpretation, peer review and other aspects of research.

- Integrity by keeping agreements and acting sincerely.

- Carefulness by avoiding careless errors, negligence, and by accurate record keeping.

- Confidentiality by keeping communications and participants' responses anonymous.

- Responsible publication for the purpose of advancing knowledge and scholarship and not just for promotion.

- Responsible monitoring to help educate students and junior academics for their advancement. These and other ethical issues should be adhered to in conducting research or choosing research topics.

\section{Guidelines for Choosing a Good Research Topic in Education}

A research topic is derived from a research problem. The topic summarizes and collapses the main idea of a research problem into a researchable statement. The statement must depict the purpose of the research and determines the research design or type of research being conducted. Inability to generate research topics is a common problem among students.

Choosing a research topic requires a lot of skills. It contains the main idea of the research problem and should be concise and capture the problem elements of the study. The research topic must also identify the actual variables under study. 
The following guidelines/procedures will assist in selecting a good research topic:

- The researcher must identify a problem first before framing the topic to suit it.

- The topic should reflect two components; independent variable(s), dependent variable(s) e.g. impact of school environment on students' achievement in Health Science.

- The topic must fall within the discipline in time and space. That is, the topic must fall within education or related to education.

- It must address important problem in education.

- The topic should be of interest to the researcher. This will sustain the attention of the researcher throughout the investigation.

- The researcher should have knowledge on the topic. The topic should be an area where the research is competent or area of his expertise.

- The topic must be informative. The topic should convey sufficient information on the nature of the research problem or study.

- The topic should not be too lengthy (should be between 12 and 18 words and not more than 22).

- It must be such that can be investigated within a specified period.

- The scope in terms of content and geographical area of coverage must be clearly stated.

- The researcher must understand the magnitude and dimension of the problem before looking for the appropriate topic for it. Also, other considerations in choosing a research topic include:

- Feasibility: Consider the complexity of the problem and the resources you will require to carry out the study.

- Acceptability: It is advisable to research a topic that has the interest and support of the authorities. This will facilitate the smooth conduct of the research and increases the chance that the results of the study will be implemented.

- Ethical acceptability: the researcher should always consider the possibility that may inflict harm on others while carrying out research. Therefore, it will be useful to review the proposed study.

\section{Conclusion}

Many researchers have failed to provide tangible solutions to education related problems because they lack mastery in the act of researchable topics. Again, having the knowledge is not enough but putting it into practice is what makes the difference. As these guidelines outlined in this paper are applied, research will become a rewarding experience and proffer solutions to many educational problems.

\section{References}

i. Adiele, E.E. (2016). A guide to research in education. Port Harcourt: Harey publications.

ii. Ajoku, L.I. (2006). Foundations of educational research and statistics. Port Harcourt, Nigeria: Pearl publishers.

iii. Kpolovie, P.J (2010). Advanced research methods. Imo State: Springfield publishers Ltd.

iv. Maduabum, M.A. (2007). Fundamentals of educational research. Port Harcourt: Firstborn printers.

v. Ugodulunwa, C.A. (2016). Basics of academic writing: A guide for students. Jos: Fab Anieh Nigeria Ltd.

vi. Aliakwo, M.J. (2003). Foundations of educational research. Port Harcourt: Manson publishers.

vii. Anusiem, A. U. (1992). An overview of educational research. In Isangedighi, A.J. and Ogomaka, P. M.C. (Eds.), Educational Research Methods. Owerri: Totan Publishers Ltd.

viii. Ukwuije, R. P. I. (2007).Introductory research methods and statistics in education. Port Harcourt: Cewil Nigeria Limited. 